Article

\title{
Experimental Investigation into the Structural and Functional Performance of Graphene Nano-Platelet (GNP)-Doped Asphalt
}

\author{
Murryam Hafeez ${ }^{1, *(\mathbb{D}, \text { Naveed Ahmad }}{ }^{1}$, Mumtaz Ahmed Kamal ${ }^{1}$, Javaria Rafi ${ }^{1}$, \\ Muhammad Faizan ul Haq ${ }^{1}{ }^{(\mathbb{C}}$, Jamal ${ }^{2}$, Syed Bilal Ahmed Zaidi ${ }^{1}$ and Muhammad Ali Nasir ${ }^{3}$ (D) \\ 1 Department of Civil Engineering, University of Engineering and Technology Taxila, Taxila 47080, Pakistan; \\ n.ahmad@uettaxila.edu.pk (N.A.); drmakamal@yahoo.com (M.A.K.); javariarafi@outlook.com (J.R.); \\ faizan.ul@students.uettaxila.edu.pk (M.F.u.H); bilal.zaidi@uettaxila.edu.pk (S.B.A.Z.) \\ 2 Department of Civil Engineering, Royal Melbourne Institute of Technology University, Victoria 3053, \\ Australia; jamal.naasir209@gmail.com \\ 3 Department of Mechanical Engineering, University of Engineering and Technology Taxila, Taxila 47080, \\ Pakistan; ali.nasir@uettaxila.edu.pk \\ * Correspondence: murryamhafeez77@outlook.com; Tel.: +92-3222189592
}

Received: 28 December 2018; Accepted: 13 February 2019; Published: 17 February 2019

\begin{abstract}
With the increase in the demand for bitumen, it has become essential for pavement engineers to ensure that construction of sustainable pavements occurs. For a complete analysis of the pavement, both its structural and functional performances are considered. In this study, a novel material (i.e., Graphene Nano-Platelets (GNPs)) has been used to enhance both of the types of pavements' performances. Two percentages of GNPs (i.e., $2 \%$ and $4 \%$ by the weight of the binder) were used for the modification of asphalt binder in order to achieve the desired Performance Grade. GNPs were homogeneously dispersed in the asphalt binder, which was validated by Scanning Electron Microscope (SEM) images and a Hot Storage Stability Test. To analyze the structural performance of the GNPs-doped asphalt, its rheology, resistance to permanent deformation, resistance to moisture damage, and bitumen-aggregate adhesive bond strength were studied. For the analysis of the functional performance, the skid resistance and polishing effect were studied using a British Pendulum Skid Resistance Tester. The results showed that GNPs improved not only the rutting resistance of the pavement but also its durability. The high surface area of GNPs increases the pavement's bonding strength and makes the asphalt binder stiffer. GNPs also provide nano-texture to the pavement, which enhances its skid resistance. Thus, we can recommend GNPs as an all-around modifier that could improve not only the structural performance but also the functional performance of asphalt pavements.
\end{abstract}

Keywords: Graphene nano-platelets (GNPs); asphalt; Scanning Electron Microscope (SEM); structural performance; functional performance

\section{Introduction}

Bitumen is considered to be an essential component of roadways and its demand is increasing with each passing day. According to the Asphalt Institute, 87 million tons of bitumen are produced per year around the globe [1]. A major chunk of this production, approximately $85 \%$ of the bitumen, is used in the paving industry. With the increase in traffic loads, the need for progress in pavement technology is also increasing. The early failure of pavement calls for its reconstruction, which results in an increased demand for bitumen. In order to conserve the resources, it is necessary to ensure the construction of sustainable pavements. 
In Pakistan, two commonly observed highway failures are rutting and moisture damage. The poor mix properties of asphalt and the high temperature greatly contribute to these failures. The temperature cannot be controlled; however, the properties of asphalt can be improved for better temperature resistance. For over 50 years, researchers have been using various asphalt modifiers to achieve the desired material properties. Recently, the use of nanoparticles for asphalt modification has been brought into the hot spot because of their unique properties. Researchers have used various kinds of nanoparticles for enhancing the properties of asphalt, such as Nanosilica, Carbon Nanotubes (CNTs), Carbon Black Nanoparticles (CBNPs), and Graphite Nanoparticles (xGNPs). Graphene Nano-Platelets (GNPs) have commendable mechanical and thermal properties and as a result, their applications can be found in a broad range of fields [2-5]. A high specific surface area (SSA) and shape ratio (diameter/thickness) are responsible for imparting these properties on GNPs [6]. The strong carbon-carbon bond not only contributes to their exceptional strength but also provides chemical and structural stability [7]. The modification of asphalt with GNPs results in enhanced adhesive forces that increase the moisture resistance of asphalt. Asphalt modified by Graphene Nano-Platelets (GNPs) has been found to have improved mechanical and compaction properties when compared to the conventional asphalt [8]. The two challenges that researchers have to face while working with nanoparticles are their high cost and difficulty in homogeneously dispersing them in an asphalt binder. While working with GNPs, researchers overcame both of these challenges, as GNPs are low in cost and it is easier to achieve their homogeneous dispersion in an asphalt binder [8,9].

Researchers use a wet mixing technique to disperse nanoparticles in the binder. Nanoparticles are first dispersed in the solvent using a mechanical stirrer and then are mixed with the binder using a high shear mixer. The commonly observed issue with the wet mixing technique is that, if the solvent does not evaporate completely from the binder, it compromises the properties of the binder [1]. The usage of the solvent and the high shear mixer adds to the extra cost, as well as increases the processing time. On the other hand, it is comparatively easy to disperse GNPs in the asphalt binder, as no solvent or shear mixer is required. This makes the industrial application of GNPs favorable.

In order to evaluate a pavement, a structural and functional analysis of it is carried out. The structural performance is related to the pavement's strength and capacity to carry loads and traffic flow during its service life. The functional performance relates to the roughness of the pavement's surface. The skid resistance is an important parameter of the functional performance when it comes to the safety of the pavement. It is influenced by the micro-texture and the macro-texture of the pavement. The micro-texture affects the skid resistance in the pavement's early life, whereas the macro-texture influences the skid resistance over the service life of the pavement. To study the micro-texture and macro-texture of asphalt, Scanning Electron Microscopy and a British Pendulum Skid Resistance Tester are used. The structural and functional performances are inter-dependent. In a structurally sound pavement, the macro-texture remains intact for a longer period of time, providing skid resistance [10]. Normally, the gradation of aggregates is altered to get the desired skid resistance. In this study, we have worked with GNPs to improve the structural and functional performances of pavement, using a single modifier at the same time.

As the introduction of GNPs into the world of pavements happened quite recently, their impact on the rutting resistance, moisture susceptibility, and skid resistance of the asphalt needs further exploration. This paper not only aims to study the structural performance of asphalt modified by GNPs but to also explore its functional performance.

\section{Materials and Methods}

\subsection{Materials}

\subsubsection{Graphene Nano-Platelets}

Graphene Nano-Platelets are basically sheets of graphene piled up together. A single graphene sheet is a monolayer of carbon atoms. These carbon atoms are tightly packed in a hexagonal 
arrangement. The stacking, rolling, and wrapping of graphene results in the formation of graphite, CNTs, and fullerenes, respectively. Thus, graphene can be labeled as a building block in the formation of the allotropes of carbon [11].

For this study, GNPs were procured from Advanced Chemical Suppliers (ACS) Materials, Pasadena, CA, USA. These GNPs were prepared using the interlayer cleavage method. Table 1 shows the properties of the procured GNPs. The shape ratio (diameter/thickness) and specific surface area are the two main properties of GNPs that are responsible for imparting the structural strength to GNPs-doped asphalt.

Table 1. The properties of Graphene Nano-Platelets (GNPs).

\begin{tabular}{cc}
\hline Appearance & Black/Grey Powder \\
\hline Diameter & $2-7 \mu \mathrm{m}$ \\
Thickness & $2-10 \mathrm{~nm}$ \\
Specific Surface Area & $20-40 \mathrm{~m}^{2} / \mathrm{g}$ \\
Electrical Conductivity & $80,000 \mathrm{~S} / \mathrm{m}$ \\
Carbon Content & $>99 \%$ \\
Apparent Density & $0.06-0.09 \mathrm{~g} / \mathrm{ml}$ \\
Water Content & $<2 \mathrm{wt.} \%$ \\
Residual Impurities & $<1 \mathrm{wt.} \%$ \\
Unit Price & $\$ 1.9 / \mathrm{gram}$ \\
\hline
\end{tabular}

\subsubsection{Bitumen}

For this study, 60/70 Penetration Grade bitumen was used. It was procured from the Attock Oil Refinery Limited, Pakistan.

\subsubsection{Aggregates}

The source of the aggregates used for this research was Margalla Quarry, Punjab, Pakistan. It is a local quarry of limestone. Table 2 shows the qualitative properties of the aggregates obtained from the Margalla Hills [12].

Table 2. The properties of the aggregates procured from Margalla Quarry.

\begin{tabular}{cccc}
\hline Material Properties & Standard & Results (\%) & NHA * Specification Limits \\
\hline Fractured particles & ASTM D5821 & 100 & $90 \%(\min )$ \\
Flakiness & BS 812.108 & 4.75 & $10 \%(\max )$ \\
Elongation & BS 812.109 & 2.2 & $10 \%(\max )$ \\
Sand equivalent value & ASTM D 2419 & 75 & $50 \%(\min )$ \\
Los Angeles abrasion & ASTM C 131 & 23 & $30 \%(\max )$ \\
Water absorption & ASTM C 127 & 1.02 & $2 \%(\max )$ \\
Soundness (Coarse) & ASTM C 88 & 7.1 & $8 \%(\max )$ \\
Soundness (Fine) & ASTM C 88 & 4.7 & $8 \%(\max )$ \\
Uncompacted voids & ASTM C 1252 & 45.5 & $45 \%(\min )$ \\
\hline
\end{tabular}

* National Highway Authority.

The National Highway Authority Class B (for wearing course), which is specified as a finer gradation, was used for the preparation of the asphalt mixtures. Figure 1 represents the midpoint gradation curve for the National Highway Authority (NHA) Class B. 


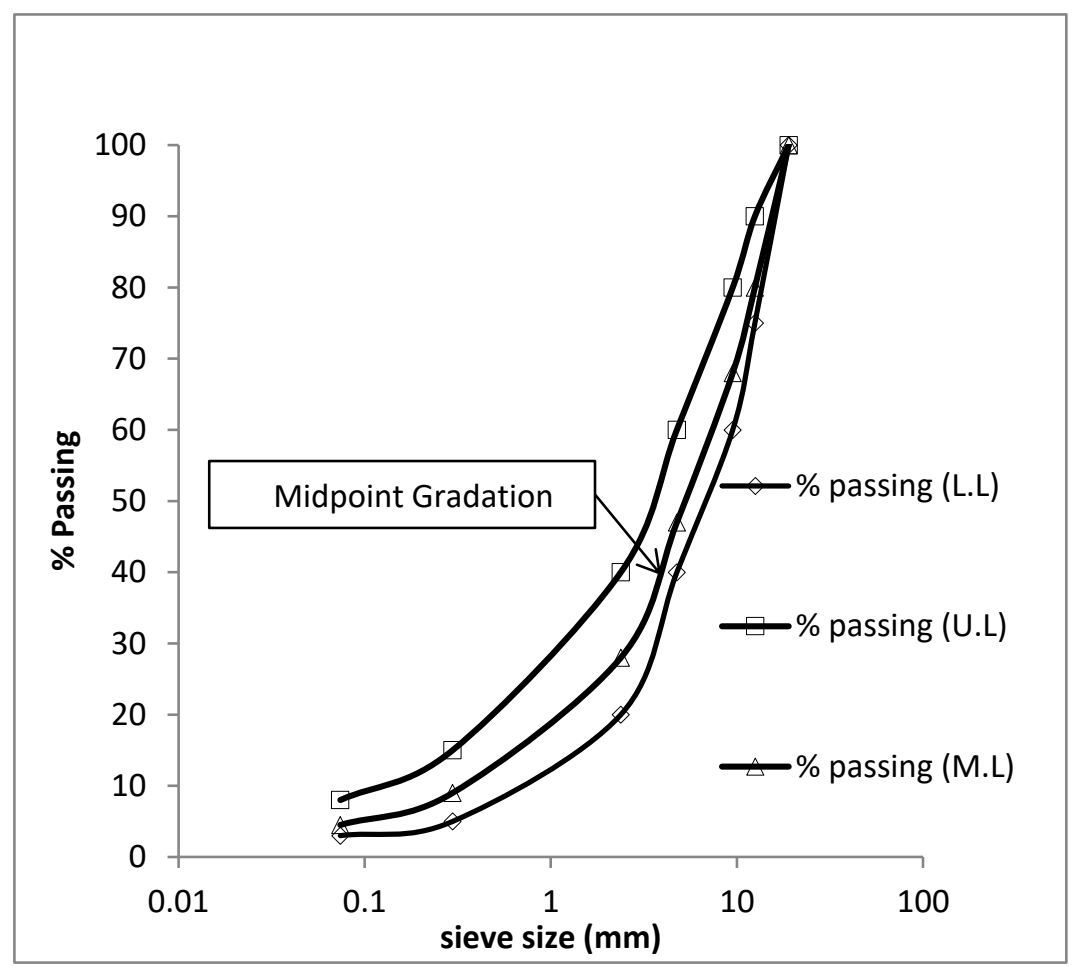

Figure 1. The aggregate gradation curve.

\subsection{Preparation of GNP-Modified Asphalt}

In Pakistan, the asphalt binder selection is currently based upon penetration grading, whereas pavement engineers around the globe are adopting performance grading (PG). The concept of performance grading is based around the idea that the properties of the asphalt binder should be in accordance with the requirements put forth by the environmental conditions of the area in which it is used. According to the temperature zoning of Pakistan, in $70 \%$ of areas the required performance grade of a binder is 70-10 [13,14]. Unfortunately, PG 70-10 binder is not produced in any of the oil refineries in Pakistan [13]. The PG of the binder used in this study was 58-22, which is much softer than the required PG 70-10. The high PG values are more of a concern, as the temperature hardly falls below 0 ${ }^{\circ} \mathrm{C}$ in most of the areas of Pakistan. The aim of the study was to achieve a PG of 70 using GNPs. For this research, two percentages of GNPs were used ( $2 \%$ and $4 \%$ ) by weight ( $23 \%$ and $46 \%$ by volume) of the binder. This choice was made on the basis of the performance grade, as PG 64 was achieved when $2 \%$ of GNPs were added to the binder and PG 70 was achieved upon the addition of $4 \%$ of GNPs. For performance grading, a Dynamic Shear Rheometer was used. The frequency was set as $10 \mathrm{rad} / \mathrm{s}$ and $25 \mathrm{~mm}$ geometry was used. The initial temperature was set at $58{ }^{\circ} \mathrm{C}$. The highest temperature, where the value of $\mathrm{G}^{*} / \sin \delta(\mathrm{kPa})$ was reduced to $1.0 \mathrm{kPa}$ or less, was termed the high-temperature performance grade $(\mathrm{PG})$ of the binder. The variation in the performance grade of the binder after its modification with GNPs is presented in Figure 2. The PG of the base binder was $58^{\circ} \mathrm{C}$ and it failed at $62.7^{\circ} \mathrm{C}$. Upon the addition of $2 \%$ of GNPs, the PG increased by one level, i.e., $64{ }^{\circ} \mathrm{C}$. The failure temperature also increased from $62.7^{\circ} \mathrm{C}$ to $65.7^{\circ} \mathrm{C}$. A more pronounced change was observed when $4 \%$ of GNPs were added to the asphalt binder. PG 70 was achieved after modifying the binder with $4 \%$ of GNPs and the failure temperature was $71.5^{\circ} \mathrm{C}$. The trend shows that, with the addition of GNPs to the asphalt binder, its performance grade increases.

Prior to the mixing process, the asphalt binder was heated in an oven for $30 \mathrm{~min}$ at $158 \pm 5^{\circ} \mathrm{C}$. A glass rod was used to mix the GNPs into the binder for $10 \mathrm{~min}$ at $158 \pm 5^{\circ} \mathrm{C}$ [8]. In order to ensure homogeneous mixing of the GNPs in the asphalt binder, Scanning Electron Microscope (SEM) (Vega3, TESCAN, Czech Republic) images were taken. The Scanning Electron Microscope has been shown in 
Figure 3. Figure 4 shows the SEM image of the GNPs, in which the plate-like/flaky morphology of the GNPs can be seen. Figure 5 is the SEM image of the GNPs dispersed in the asphalt binder. In the image, homogeneously dispersed GNPs are visible in the binder.

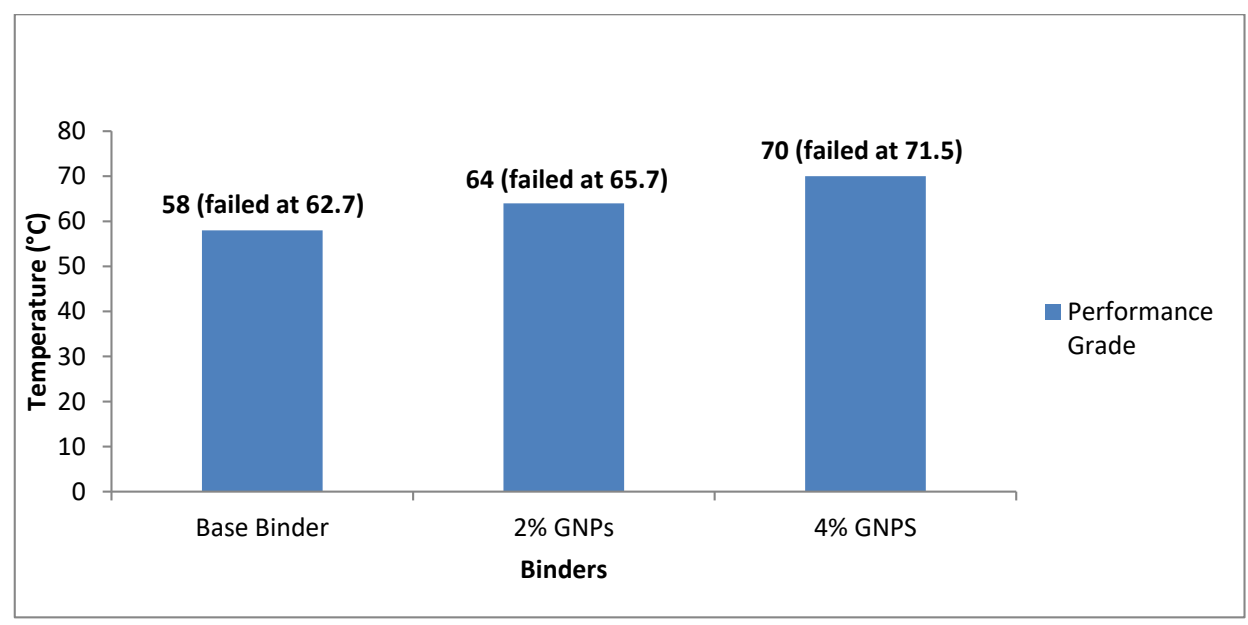

Figure 2. The performance grades (PGs) of the asphalt binders.

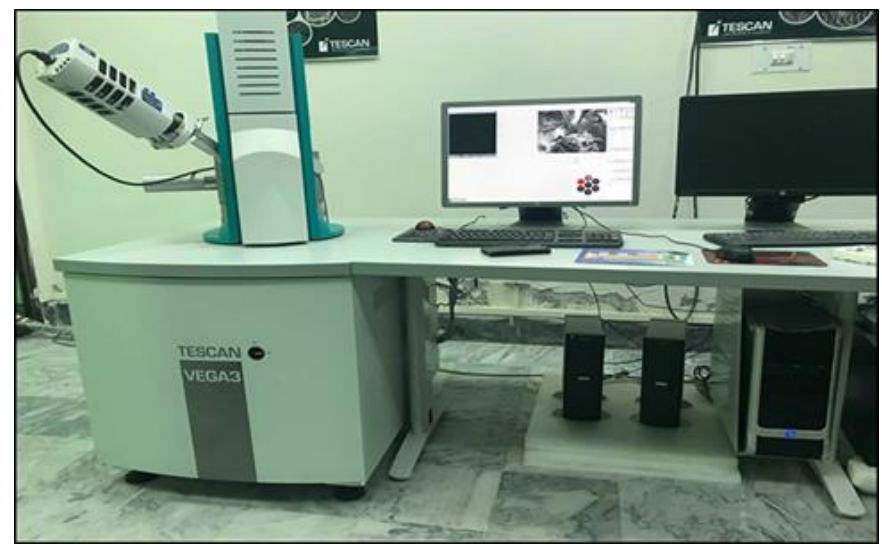

Figure 3. The Scanning Electron Microscope (SEM) in the Mechanical Engineering Department (University of Engineering and Technology, Taxila).

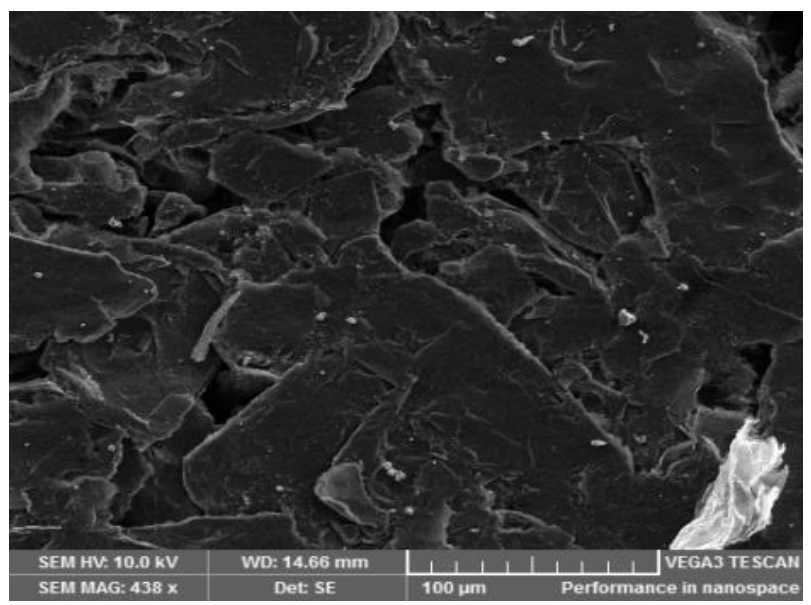

Figure 4. A Scanning Electron Microscope (SEM) image of the Graphene Nano-Platelets (GNPs) $(100 \mu \mathrm{m})$. 


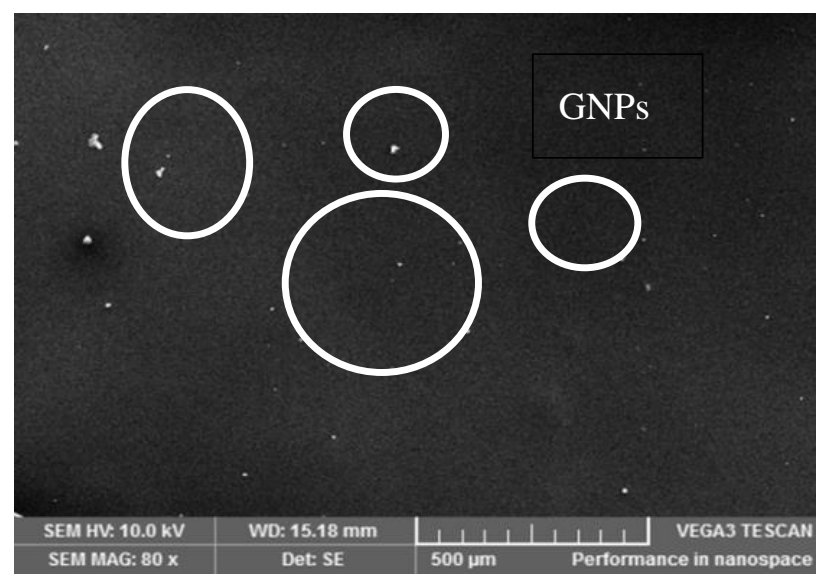

Figure 5. A Scanning Electron Microscope (SEM) image of the Graphene Nano-Platelets (GNPs) in the asphalt binder $(500 \mu \mathrm{m})$.

According to the General Specifications of the National Highway Authority (NHA) of Pakistan, two aggregate gradations named class " $\mathrm{A}$ " and " $\mathrm{B}$ " are used for the construction of asphalt pavement wearing courses. Class A is coarser, while class B is finer [15]. For this study, the asphalt mixtures were prepared using the NHA class B aggregate gradation for the wearing course (19.5 mm Nominal Maximum Aggregate Size). To determine the Optimum Binder Content (OBC) of the GNP-modified asphalt, the Marshall Method of Mix Design was adopted. The asphalt mixes were prepared using a base binder and GNP-modified binders. Throughout the design, 5.5\% of the air voids were maintained, which is the mean of the specified range of the in-place air voids ( $3 \%$ to $8 \%$ ) according to the Asphalt Institute Manual Series-2 (MS-2). The OBCs of the three types of mixes are reported in Table 3.

Table 3. The Optimum Binder Content (OBC) of the asphalt mixtures.

\begin{tabular}{cc}
\hline Type of Mix & Optimum Binder Content \\
\hline Base Binder & 4.38 \\
$2 \%$ GNPs & 4.49 \\
$4 \%$ GNPs & 4.67 \\
\hline
\end{tabular}

\subsection{Storage Stability Test}

The storage stability is an integral parameter to consider while working with binders modified with nanoparticles. A Hot Storage Stability Test was carried out to check whether the suspension of the GNPs in the bitumen was stable for storage or not. This test was performed according to BS EN 13399 (2017). During this, $50 \mathrm{~g}$ of GNP-modified binder was poured into an aluminum tube. It was kept in the oven at $163{ }^{\circ} \mathrm{C}$ for $72 \mathrm{~h}$. After the sample was taken out, it was cut into three sections. The top and bottom sections were heated and poured into rings for a softening point test. For a stable storage sample, the difference in the softening point of the top and bottom sections should be less than $2.2^{\circ} \mathrm{C}$. Although the softening point test is the most common method to determine the storage stability, it is not highly accurate [16]. For accuracy, the performance grades of all of the three sections were also determined by using a Dynamic Shear Rheometer (DSR) to ensure the homogeneous mixing of the GNPs in the binder.

The softening point results for the top and bottom sections of the tube are shown in Table 4 . 
Table 4. The softening point test results for storage stability.

\begin{tabular}{cccc}
\hline Softening Point $\left({ }^{\circ} \mathrm{C}\right)$ & Base Binder & $\begin{array}{c}\text { 2\% Graphene } \\
\text { Nano-Platelets (GNPs) }\end{array}$ & $\begin{array}{c}\text { 4\% Graphene } \\
\text { Nano-Platelets (GNPs) }\end{array}$ \\
\hline Top Section & 48.5 & 49.8 & 57.4 \\
Bottom Section & 49 & 50.5 & 57.8 \\
Difference & 0.5 & 0.7 & 0.4 \\
\hline
\end{tabular}

According to the results, the difference between the softening point of the top and bottom sections of the $2 \%$ and $4 \%$ GNP-modified binder was less than $2.2{ }^{\circ} \mathrm{C}$. This indicates that the GNP-modified asphalt binder is a stable storage blend [17].

The performance grades of the top and bottom sections of the samples for all of the blends were also determined using a DSR to ensure the homogeneous dispersion of the GNPs in the asphalt binder, as the rheological characterization of the binder is affected by its composition [16]. The performance grades of the binders did not vary between the sections.

\subsection{Study of the Structural Performance}

\subsubsection{Conventional Testing and Rheological Analysis of the Binder}

\section{- Conventional Binder Testing}

The penetration, softening point, and ductility tests were performed in accordance with ASTM D5-13, ASTM D36-76, and ASTM D113-99, respectively.

- Study of the Rheology of the Binder Using a Dynamic Shear Rheometer

The rheological parameters of the binder, such as the Complex shear modulus $\left(G^{*}\right)$, Phase angle $(\delta)$, and Superpave Rutting factor $\left(\mathrm{G}^{*} / \sin \delta\right)$, were determined using an Anton Paar Dynamic Shear Rheometer (DSR). Two tests were performed in accordance with AASHTO T 315 (High-Temperature Performance Grading and a Frequency Sweep Test).

The range of frequencies used for the frequency sweep test was 10 to $0.1 \mathrm{rad} / \mathrm{s}$. The range of temperatures used was $20^{\circ} \mathrm{C}$ to $70{ }^{\circ} \mathrm{C}$. Both of the geometries $(8 \mathrm{~mm}$ and $25 \mathrm{~mm})$ were used. In this test, oscillatory shear stress is used at a constant strain level to determine the storage and loss modulus at the given range of frequencies and temperatures. The test data obtained were fitted to develop master curves using the sigmoidal function, as described by the mechanistic-empirical pavement design guide (MEPDG). Master curves were constructed at a reference temperature of $50^{\circ} \mathrm{C}$ by giving a horizontal shift to the data obtained from each test temperature. A temperature of $50{ }^{\circ} \mathrm{C}$ was selected because the main focus of the study was to analyze the high-temperature performance of the binder. Before the Frequency Sweep test, a Strain Sweep test was performed at each testing temperature in strain-controlled mode. The complex shear modulus $\left(G^{*}\right)$ was measured and the percent strain value at which the complex shear modulus was reduced to $95 \%$ of its initial value was noted as a threshold for the linear viscoelastic (LVE) region. Based on this, the strain limit for the base binder was kept at $10 \%$, whereas it was $0.45 \%$ for the GNP-modified binder.

\subsubsection{Permanent Deformation Analysis}

- Study of the Rut Resistance

The rut resistance of asphalt was studied at $40{ }^{\circ} \mathrm{C}$ and $55^{\circ} \mathrm{C}$ using a Cooper Wheel Tracking Machine. The standard followed for this test was BS EN12697-22. The asphalt mix was prepared at $158 \pm 5{ }^{\circ} \mathrm{C}$ and compacted to form slabs, with the help of a compacting machine, until the target of $5.5 \%$ air voids was achieved. Three slabs were prepared for each test condition. The dimensions of the slabs were $305 \mathrm{~mm} \times 305 \mathrm{~mm} \times 50 \mathrm{~mm}$. The load applied by the wheel tracking machine was $700 \mathrm{~N}$. The thickness of the wheel was $50.8 \mathrm{~mm}$ and its diameter was $203.2 \mathrm{~mm}$. The speed of 
the machine was $26.5 \mathrm{rpm}$. Each slab was subjected to 10,000 loading cycles and the rut depth was measured. The wheel-tracking slope should be expressed in mm per $10^{3}$ load cycles and calculated using Formula (1).

$$
W T S_{A I R}=\left(d_{10000}-d_{5000}\right) / 5
$$

where $W T S_{A I R}$ is the wheel-tracking slope ( $\mathrm{mm} / 10^{3}$ load cycles) and $d_{5000}$ and $d_{10000}$ are the rut depths (mm) after 5000 load cycles and 10,000 load cycles, respectively.

- Determination of the Dynamic Modulus of Asphalt

The ratio of the peak-to-peak stress to the peak-to-peak strain is termed the Dynamic Modulus. A Dynamic Modulus test was performed using the Servo-Pneumatic Universal Testing Machine NU-14 (Cooper, Ripley, UK). This test is also termed as a viscoelastic test in which sinusoidal loading is applied. The standard followed for this test was in accordance with AASHTO TP 62-8. Cylindrical specimens of asphalt were prepared using a Superpave Gyratory Compactor (Controls, Milan, Italy), with a diameter of $152.4 \mathrm{~mm}$ and a height of $172.72 \mathrm{~mm}$. Samples with a diameter of $101.6 \mathrm{~mm}$ and a height of $152.4 \mathrm{~mm}$ were extracted using a core cutter machine. Three samples were prepared against each test condition. The test was performed at $40{ }^{\circ} \mathrm{C}$ and $55^{\circ} \mathrm{C}$. The loading frequencies were $25,10,5$, 1, 0.5, and $0.1 \mathrm{~Hz}$. The loads applied at $40{ }^{\circ} \mathrm{C}$ and $55^{\circ} \mathrm{C}$ were $195 \mathrm{kPa}$ and $53 \mathrm{kPa}$, respectively. The Dynamic Modulus was recorded with the help of Linear Variable Differential Transformers (LVDTs).

\subsubsection{Durability Analysis}

- Moisture Susceptibility Analysis (Rolling Bottle Test)

A Rolling Bottle test was carried out to study the moisture sensitivity of the asphalt. The test was performed in accordance with BS EN 12697-11:2005. The $6.3 \mathrm{~mm}$ to $10 \mathrm{~mm}$ of aggregates' fraction sieved was used as per the standard EN 12697-2. The weight of the aggregates was $170 \mathrm{~g}$. The weight of the binder was $8 \mathrm{~g}$. The aggregates were heated and uniformly coated with the binder. $150 \mathrm{~g}$ of aggregate coated with binder was placed in the bottle. $400 \mathrm{~mL}$ of distilled water was added to the bottle. Two samples were prepared against each binder. All of the bottles were placed in the rolling bottle machine. The speed of the machine was 60 revolutions per minute. The samples were taken out and studied for the percentage of bitumen coverage after $6,24,48$, and $72 \mathrm{~h}$.

- Bitumen-Aggregate Adhesion Analysis

The Bitumen Bond Strength was studied using a Pneumatic Adhesion Tensile Test Instrument (PATTI). The standard followed for this test was ASTM D 4541. Plates of limestone were prepared by cutting out slabs. The dimensions of the slabs were $381 \mathrm{~mm} \times 152.4 \mathrm{~mm} \times 50.8 \mathrm{~mm}$. The slabs were cleaned for $60 \mathrm{~min}$ in an ultrasonic cleaner at $60^{\circ} \mathrm{C}$ and then heated in the oven at $150{ }^{\circ} \mathrm{C}$ for an hour. Prior to the start of the test, the binder, stubs, and slabs were heated in the oven for $30 \mathrm{~min}$ at $75{ }^{\circ} \mathrm{C}$. The type of stubs used for the test was F-4, with a diameter of $12.7 \mathrm{~mm} .0 .04 \mathrm{~g}$ of bitumen was placed on the stub and then the stub was placed on the slab. Three samples were prepared against each binder. The samples were tested after $12 \mathrm{~h}$ of conditioning at room temperature. The PATTI gives the value of burst pressure at which the stub gets detached from the substrate, which was converted to the Pull-Off Tensile Strength (POTS) by using the following Formula (2).

$$
\text { POTS }=[(B P * A g)-C] / A p s
$$

where:

$A g=$ Contact area of the gasket with the reaction plate $=2619.35 \mathrm{~mm}^{2}$

$B P=$ Burst pressure $(\mathrm{MPa})$

Aps $=$ Area of the pull stub $=126.64 \mathrm{~mm}^{2}$

$C=$ Piston Constant $=129.73 \mathrm{~g}$. 


\subsection{Study of the Functional Performance}

\subsubsection{Study of the Surface Texture}

In order to study the surface texture of aggregates coated with GNP-modified binder, images from a digital camera were captured. To observe it in detail, SEM images were used. The samples were prepared and sputtered before observation under the SEM.

\subsubsection{Study of the Skid Resistance and Polishing Effect}

A British Pendulum Skid Resistance Tester was used to study the skid resistance of the asphalt. This test was performed in accordance with ASTM E303-93(2013). Before subjecting the asphalt slabs to the Wheel Tracking Machine, their surfaces were tested for their skid resistance. The British Pendulum Skid Resistance Tester gave us a British Pendulum Number (BPN) against each asphalt mix. The higher the BPN, the higher the skid resistance is. After the completion of the Wheel Tracking Test (10,000 loading cycles), the skid resistance was checked again on the path developed due to the continuous movement of the wheel. This was done in order to study the polishing of the asphalt surface due to the movement of the wheel on the asphalt.

\section{Results and Discussion}

\subsection{Conventional Testing Results}

The results of the conventional tests performed in the laboratory to study the physical properties of the binders are presented in Table 5 .

Table 5. The physical properties of the base and modified binders.

\begin{tabular}{cccc}
\hline Test & Base Binder & $\begin{array}{c}\text { 2\% Graphene } \\
\text { Nano-Platelets (GNPs) }\end{array}$ & $\begin{array}{c}\text { 4\% Graphene } \\
\text { Nano-Platelets (GNPs) }\end{array}$ \\
\hline Penetration $(0.1 \mathrm{~mm})$ & 61 & 40 & 32 \\
Softening Point $\left({ }^{\circ} \mathrm{C}\right)$ & 48 & 49.5 & 57 \\
Ductility $(\mathrm{cm})$ & 100 & 14 & 13 \\
\hline
\end{tabular}

It was observed that the addition of the GNPs to the binder reduced its penetration value. Reductions of $34 \%$ and $48 \%$ in the penetration values were recorded after the addition of $2 \%$ and $4 \%$ of GNPs, respectively. An inverse relationship between the GNP content and binders' penetration value can be seen. An increase in the GNP content led to a decrease in the penetration value, which validated the stiffening of the binder. In the same way, the results of the softening point also depict the stiffening of the binder. The softening point of the binder increased up to $19 \%$ when $4 \%$ of GNPs were added. The improvement in the physical properties is due to the increase in the bonding strength after the homogeneous dispersion of GNP layers in the binder, which restricts the flow of bitumen and makes it stiffer [18]. The extremely small size and high surface area of GNPs enable them to form a strong bond with bitumen, which leads to a reduction in the penetration value and an increase in the softening point [19]. A massive reduction in the ductility was also recorded in the case of GNP-modified binder, which can be attributed to increased stiffness [20]. The trend in the physical properties of the GNP-modified binder indicates an enhancement in its high-temperature performance.

\subsection{Rheology of the Binder}

Frequency Sweep Test

Rheological changes were observed in the asphalt binder upon the addition of GNPs. An increase in the complex shear modulus and a decrease in the phase angle values were recorded. Figures 6 and 7 show the Master Curves for the Complex Shear Modulus and Phase Angle, respectively. It is 
evident in Figure 6 that modification of the binder with GNPs has led to an increase in the complex modulus. The increment in the complex modulus was more pronounced when $4 \%$ of GNPs were added in comparison to $2 \%$. Figure 7 shows a decrement in the phase angle, which is more prominent at a low frequency/high temperature. A maximum decrease in the phase angle was observed for the higher weight content of the GNPs. The value of the Superpave rutting factor also increased massively at a low frequency upon modification of the binder. This showed the same trend as the Complex Shear Modulus.

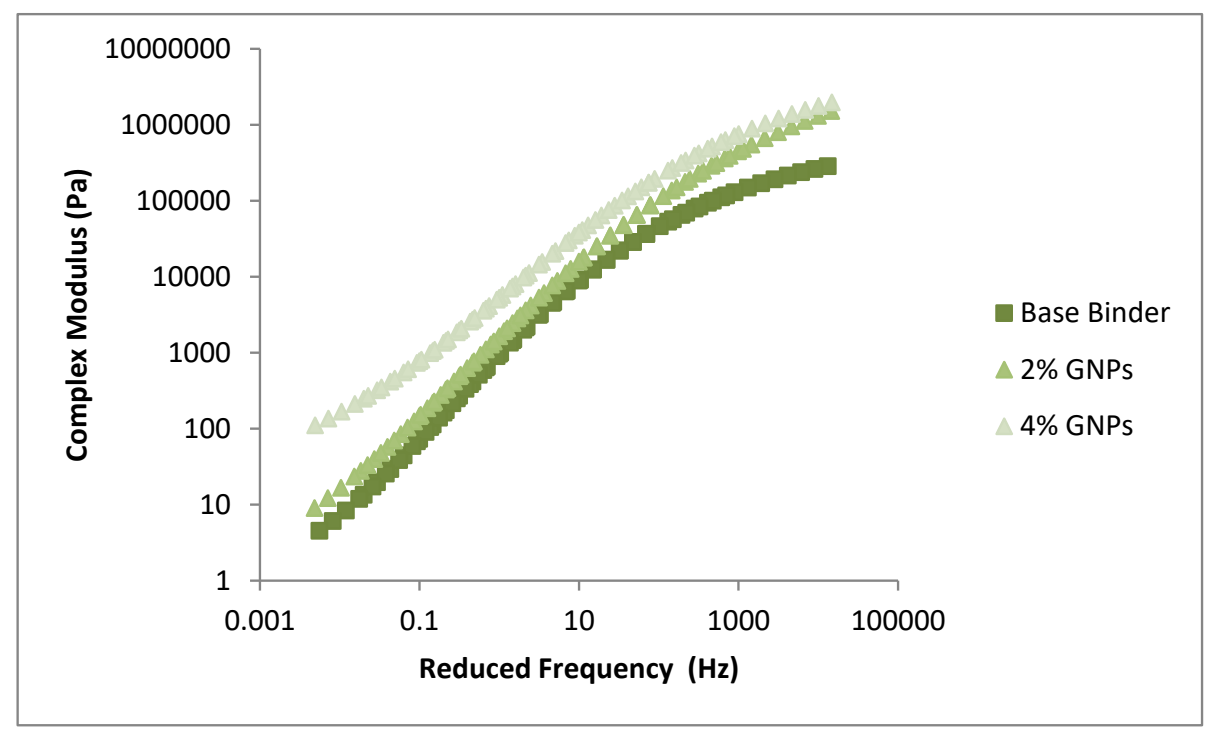

Figure 6. The Master Curve for the Complex Modulus at $50{ }^{\circ} \mathrm{C} . \mathrm{GNPs}=$ Graphene Nano-Platelets.

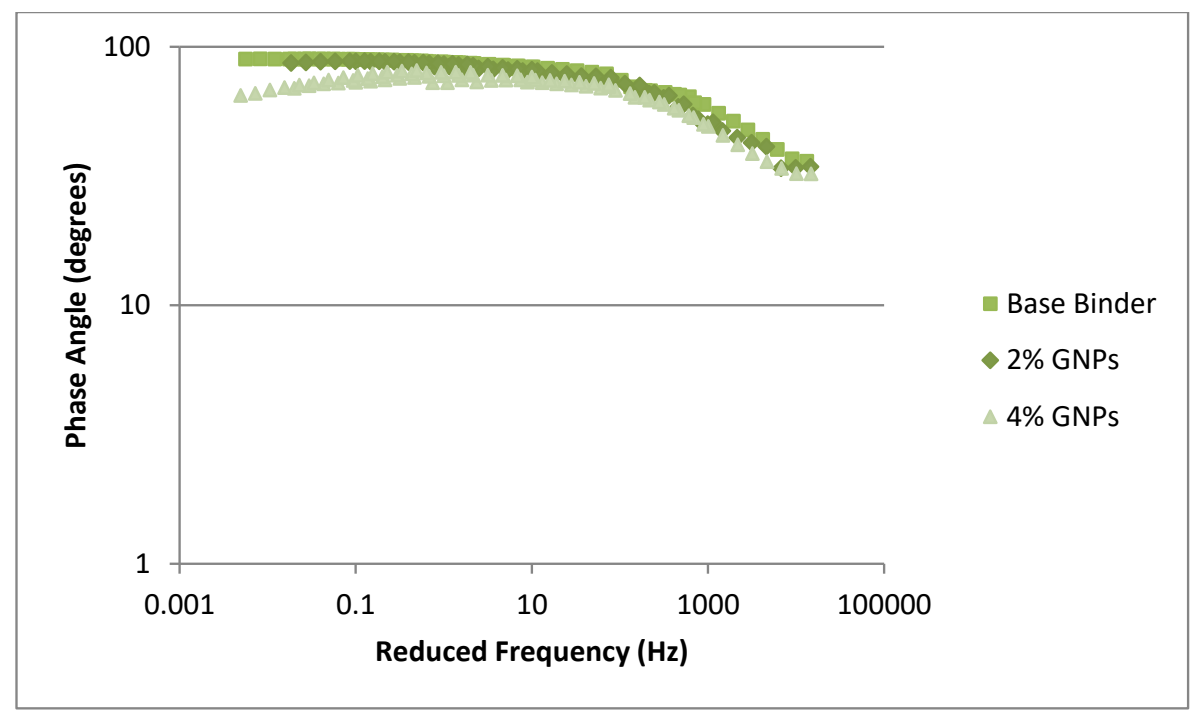

Figure 7. The Master Curve for the Phase Angle at $50{ }^{\circ} \mathrm{C}$. GNPs $=$ Graphene Nano-Platelets.

The reason behind the increase in the complex modulus can be attributed to the high elasticity and the large surface area of the nanoparticles, which gives them a higher affinity to bond with the functional groups of the binder [21]. A cover is created, which helps in preventing the viscous nature of bitumen and causes a delay in the conversion of the elastic behavior to the viscosity at a high temperature [22]. The downward shift of the phase angle can also be attributed to the elasticity of the GNPs. The elastic behavior of the asphalt binder contributes to the rutting resistance. Increasing the GNP content intensifies the increase in the complex modulus and the decrease in the phase angle. 
The increase in the Superpave rutting factor can be explained by the fact that the extremely small size of the GNPs leads to an increase in Van der Waals interaction energy between the GNPs and the asphalt binder [23]. This results in a more stable asphalt binder. The enhancement in the Superpave rutting factor due to the addition of the GNPs validates the improvement in the deformation resistance at a high temperature.

\subsection{Rutting Resistance}

The Wheel Tracking Test was performed at two temperatures $\left(40^{\circ} \mathrm{C}\right.$ and $\left.55^{\circ} \mathrm{C}\right)$. Figures 8 and 9 show the relationship between the number of passes and the rut depth for all of the samples. The results depict an enhancement in the rut resistance of the asphalt following the addition of the GNPs. The increment in the rut resistance is more pronounced at $55^{\circ} \mathrm{C}$, where the rut depth decreased from 7.3 $\mathrm{mm}$ to $4.7 \mathrm{~mm}$ after the addition of $4 \%$ of GNPs. At $40{ }^{\circ} \mathrm{C}$, the rut depth decreased from $2.8 \mathrm{~mm}$ to 2.59 $\mathrm{mm}$ when $2 \%$ of GNPs were added, and further decreased to $2.45 \mathrm{~mm}$ following the addition of $4 \%$ of GNPs. Table 6 shows the results of the Wheel Tracking Slope. It can be seen that, with the increase in the content of the GNPs, the values of the slope decrease at $55{ }^{\circ} \mathrm{C}$ and remain constant at $40{ }^{\circ} \mathrm{C}$. A decrease in the slope means that there is an increase in resistance to a permanent deformation [24]. According to the results, the maximum resistance to a permanent deformation can be achieved at 55 ${ }^{\circ} \mathrm{C}$ by adding $4 \%$ of GNPs. Due to the high surface area of the GNPs, they are reactive and form a strong bond with bitumen, imparting strength [25]. The GNPs may also act as filler, increasing the structural asphalt and significantly reducing the temperature susceptibility of asphalt [26].

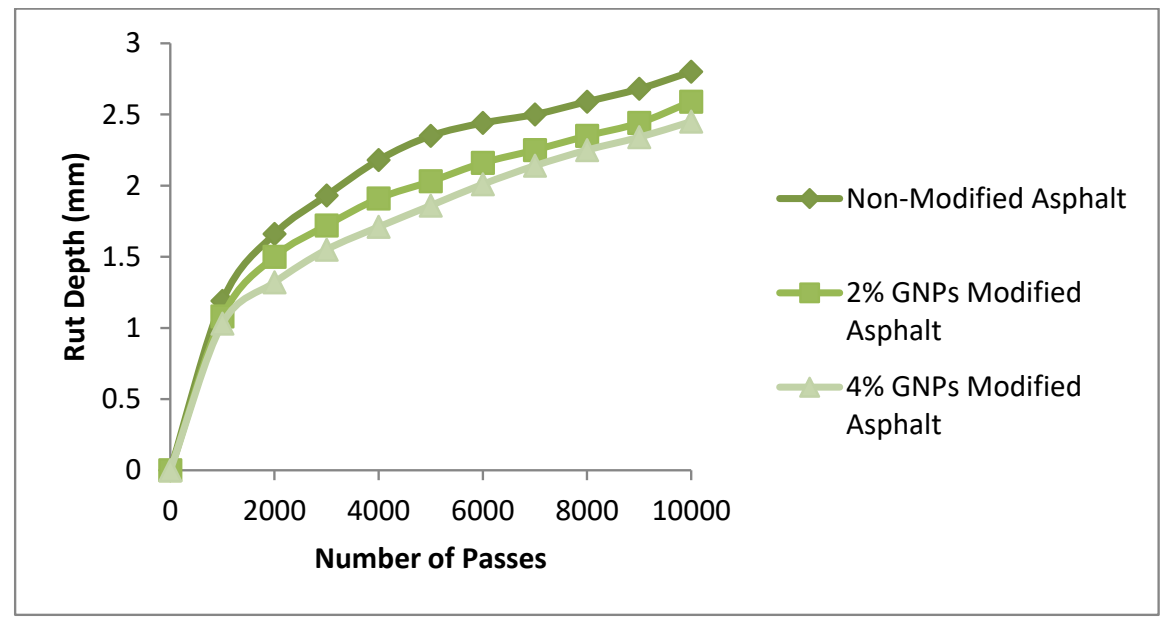

Figure 8. The Wheel Tracking Test results at $40{ }^{\circ} \mathrm{C} . \mathrm{GNPs}=$ Graphene Nano-Platelets.

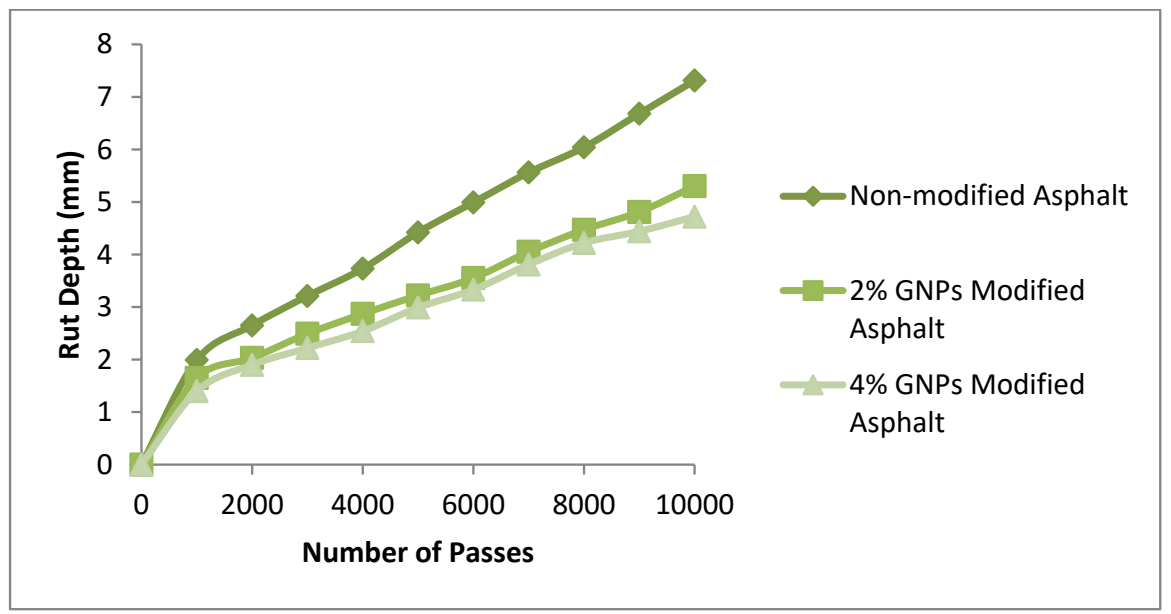

Figure 9. The Wheel Tracking Test results at $55^{\circ} \mathrm{C}$. GNPs $=$ Graphene Nano-Platelets. 
Table 6. The Wheel Tracking slope. GNPs = Graphene Nano-Platelets.

\begin{tabular}{ccc}
\hline & Wheel Tracking Slope $\left(\mathbf{m m} / \mathbf{1 0}^{\mathbf{3}}\right.$ Load Cycles) \\
\hline Temperature & $\mathbf{4 0}{ }^{\circ} \mathbf{C}$ & $\mathbf{5 5}{ }^{\circ} \mathbf{C}$ \\
\hline Non-Modified Asphalt & 0.09 & 0.58 \\
2\% GNPs Modified Asphalt & 0.11 & 0.42 \\
$4 \%$ GNPs Modified Asphalt & 0.12 & 0.35 \\
\hline
\end{tabular}

\subsection{Dynamic Modulus}

The Dynamic Modulus Test was performed using NU-14 at $40{ }^{\circ} \mathrm{C}$ and $55^{\circ} \mathrm{C}$. Figures 10 and 11 show the relationship between the frequency and the dynamic modulus for the samples at both of the temperatures. Dynamic Modulus is a direct measure of the rut resistance. It is evident from the results that the value of the Dynamic Modulus is higher for GNP-modified asphalt. Asphalt modified with $4 \%$ of GNPs gave the highest values of Dynamic Modulus, regardless of the temperature and loading conditions. The same trend has been observed in the Wheel Tracking Test too. In general, the values of the Dynamic Modulus at $55^{\circ} \mathrm{C}$ are lower than the values at $40{ }^{\circ} \mathrm{C}$, which indicates a greater rut susceptibility at a high temperature. It can also be seen that the load response lag phenomenon is quite obvious when the loading frequency increases. This indicates that the Dynamic Modulus or strength of the asphalt mixture increases with an increment in the loading frequency [27]. The well-dispersed GNPs can provide support to asphalt by increasing the interaction and adhesion strengths within it [28]. These effects may lead to an increase in the Dynamic Modulus and resistance to the rutting of GNP-doped asphalt.

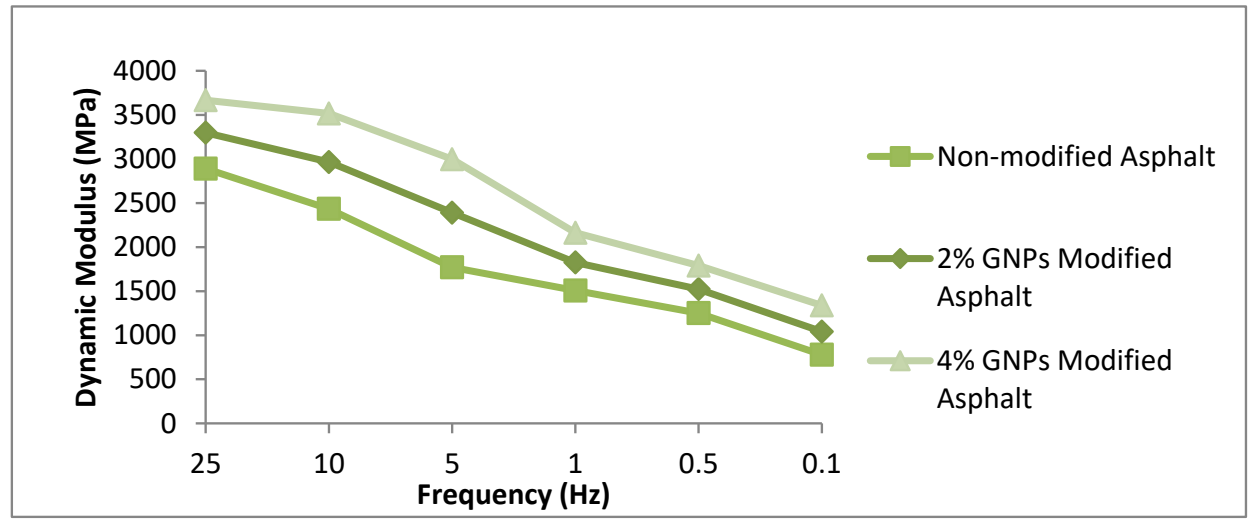

Figure 10. The Dynamic Modulus at $40^{\circ} \mathrm{C}$. GNPs $=$ Graphene Nano-Platelets.

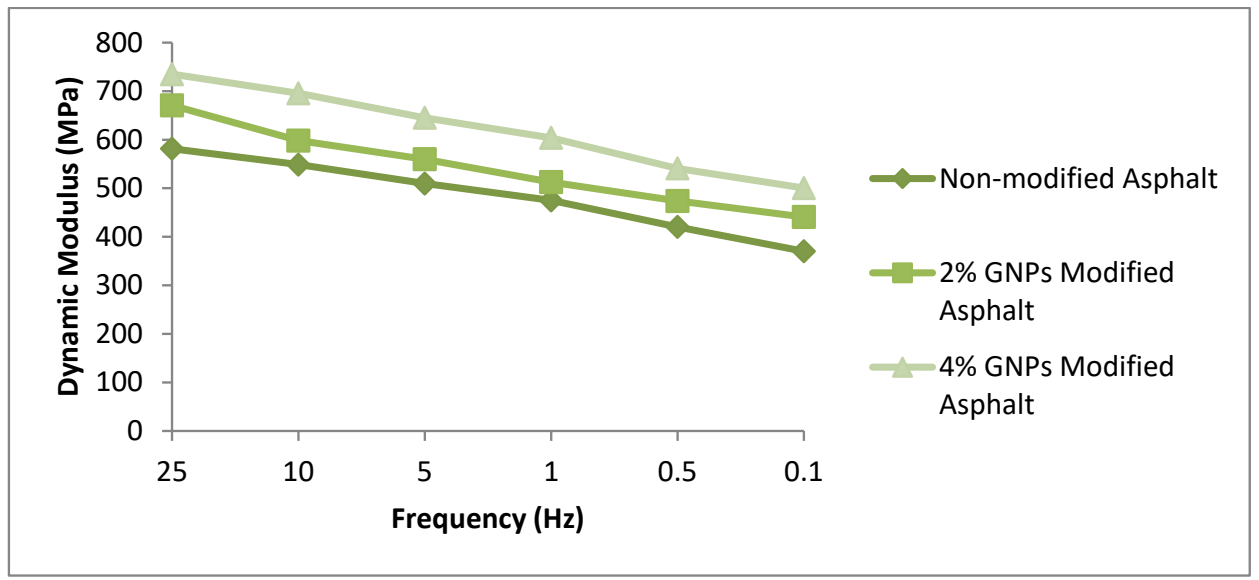

Figure 11. The Dynamic Modulus at $55^{\circ} \mathrm{C}$. GNPs $=$ Graphene Nano-Platelets. 


\subsection{Moisture Susceptibility}

The percentage of bitumen coverage was noted after $6,24,48$, and $72 \mathrm{~h}$ during the rolling bottle test. Figure 12 is the graphical representation of the relationship between the time of rolling and the percentage of bitumen coverage. Figure 13 shows the affinity between the bitumen and aggregate after $72 \mathrm{~h}$ of rolling. The rolling bottle test is a measure of the binder's moisture susceptibility. A higher percentage of bitumen coverage indicates a strong adhesive bond between the binder and the aggregate, as well as a high resistance of the binder to moisture damage. It is evident from the results that, after the completion of the test, the percentage of bitumen coverage for the base binder was $15 \%$. It then increased to $60 \%$ when $2 \%$ of GNPs were added. For the binder modified with $4 \%$ of GNPs, it jumped to $70 \%$. The extremely small size of the GNPs gives them a larger surface area compared to their parent material, which results in the increase of their affinity to form a strong bond. Thus, GNPs have the ability to absorb more free asphalt binder and maximize the quantity of the structural asphalt [26]. The results prove that the addition of GNPs leads to an increased adhesion between the binder and aggregate, making the asphalt highly resistant to moisture.

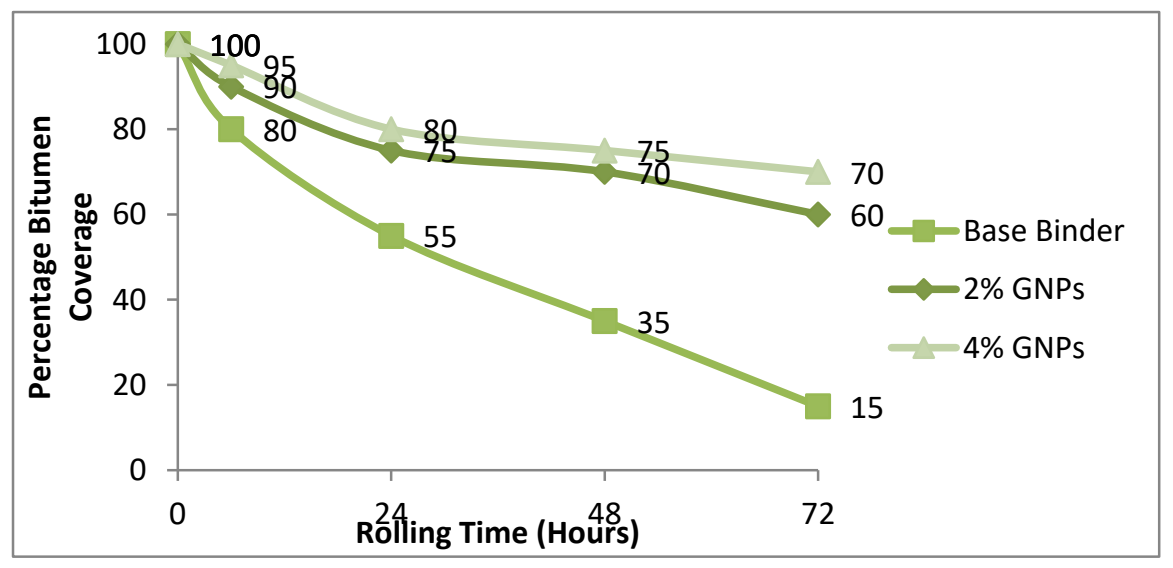

Figure 12. The Rolling Time vs the Percentage of Bitumen Coverage. GNPs = Graphene Nano-Platelets.

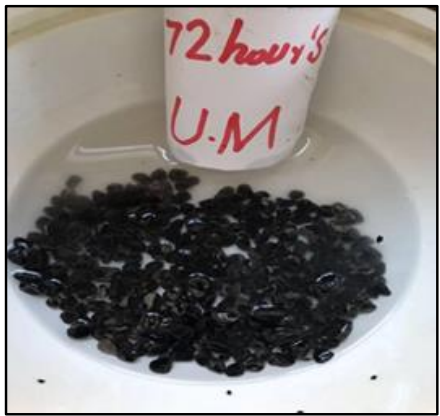

(a)

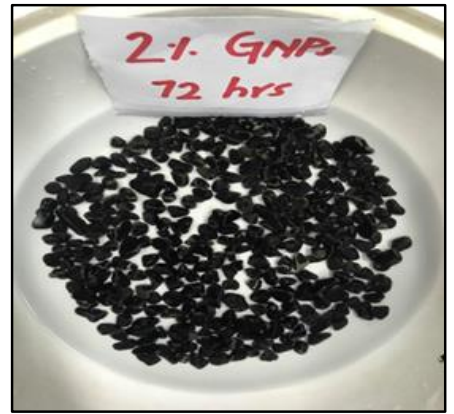

(b)

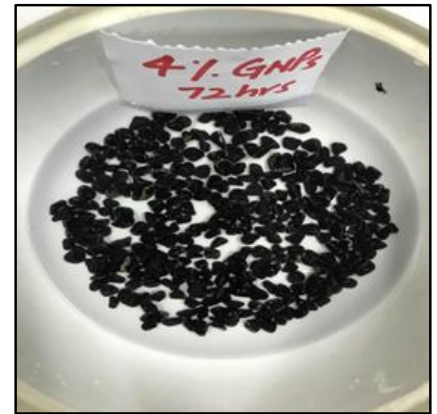

(c)

Figure 13. The bitumen/aggregate affinity after $72 \mathrm{~h}$ of rolling: (a) The base binder, (b) $2 \%$ Graphene Nano-Platelet (GNP)-modified binder and, (c) 4\% GNP-modified binder.

\subsection{Bitumen Bond Strength}

The idea of the PATTI was first conceived by the paint industry. It determines the POTS of the binder while keeping a constant loading rate of $0.69 \mathrm{MPa} / \mathrm{s}$. Figure 14 shows the testing assembly. It has been learned, from the results presented in Table 7, that an increase in additive content produces a higher Bitumen Bond Strength. When $2 \%$ of GNPs were added to the binder, the POTS increased significantly from $8.76 \mathrm{MPa}$ to $11.95 \mathrm{MPa}$. With the addition of $4 \%$ of GNPs, it further increased to 13.66 MPa. The mode of failure for all of the samples was cohesive, i.e., bitumen-bitumen interface 
breakage. The reason behind the increment in the tensile strength of the binder can be attributed to the increased surface texture of the GNP-modified asphalt binder [29]. This is because a rough binder surface is obtained when nanoparticles are added to it, due to more particle interlocking. The elasticity of the nanoparticles also plays a part in enhancing the tensile strength of the binder. Thus, it is evident that the GNPs improve the adhesive and cohesive bond strength of the asphalt binder.

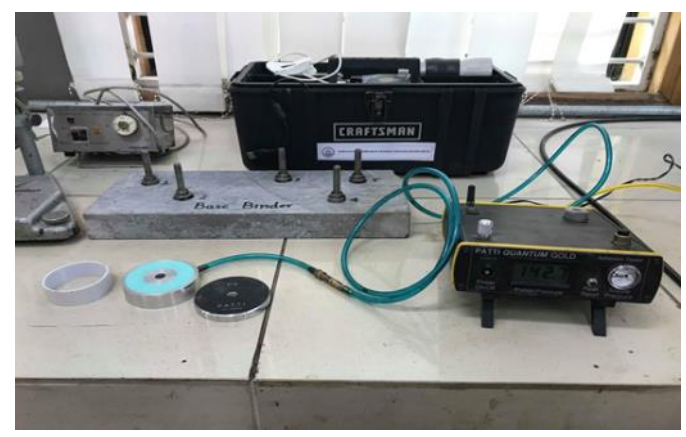

Figure 14. The Pneumatic Adhesion Tensile Test Instrument (PATTI) Assembly.

Table 7. The Pull-Off Tensile Strength (POTS) of the binder. GNPs = Graphene Nano-Platelets.

\begin{tabular}{cc}
\hline Samples & Pull-Off Tensile Strength (POTS) (MPa) \\
\hline Base Binder & \\
1 & 8.67 \\
2 & 8.76 \\
3 & 8.73 \\
2\% GNP-Modified Binder & 11.67 \\
1 & 11.95 \\
2 & 11.67 \\
3 & \\
$4 \%$ GNP-Modified Binder & 13.66 \\
1 & 13.38 \\
3 & 13.38 \\
\hline
\end{tabular}

\subsection{Surface Texture of the Binder-Coated Aggregates}

The images to study the surface texture of aggregates coated with GNP-modified asphalt binder were taken both from a digital camera and an SEM. Figure 15 shows the images of a piece of aggregate coated with base binder. Figure 16 shows the images of GNP-modified asphalt binder.

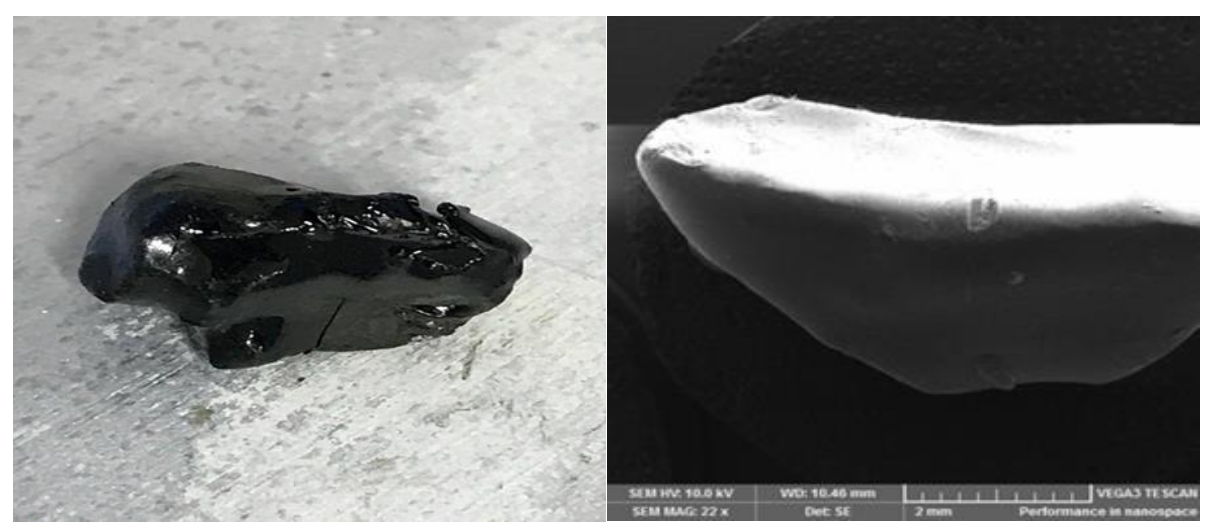

Figure 15. A piece of aggregate coated with base binder. 


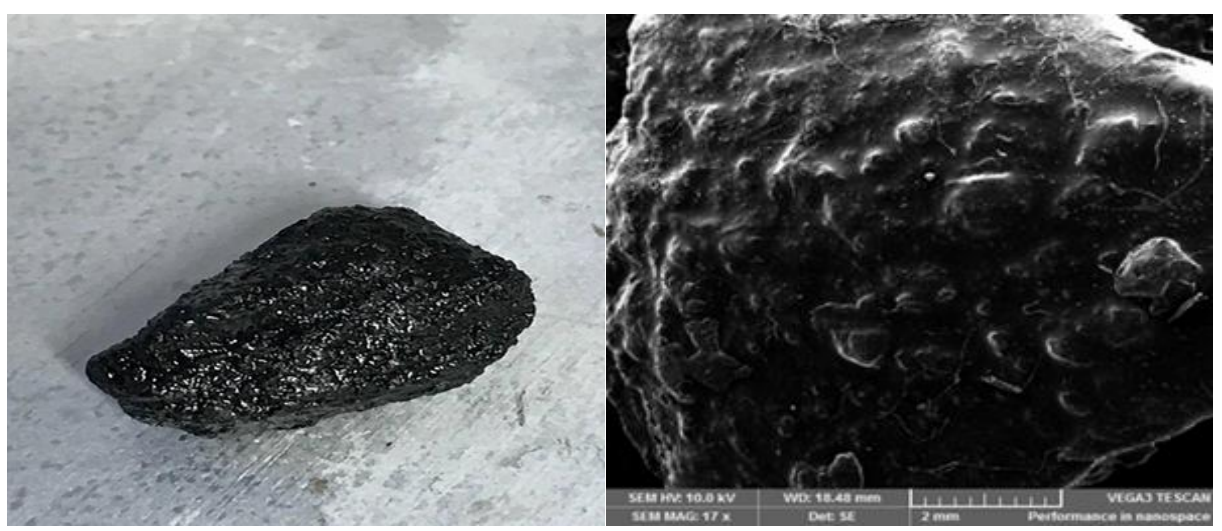

Figure 16. A piece of aggregate coated with Graphene Nano-Platelet (GNP)-modified binder.

It can be observed from the images that the surface of the aggregate coated with GNP-modified binder is rough in comparison to the one coated with the base binder. This is because nanoparticles add their nano-texture to the surface, which is also the reason that nanoparticles are used to make the pavement surface rough in order to increase its skid resistance [30].

\subsection{Skid Resistance and the Polishing Effect}

A British Pendulum Skid Resistance Tester was used to obtain the BPNs of the asphalt samples. Table 8 shows the results of the Skid Resistance test. It has been established from the results that the asphalt modified with GNPs has a higher skid resistance in comparison to non-modified asphalt. The reason behind this is the nano-texture provided by the GNPs.

Table 8. The British Pendulum Numbers (BPNs).

\begin{tabular}{|c|c|c|c|}
\hline \multicolumn{4}{|c|}{ British Pendulum Number (BPN) Before Wheel Tracking Test } \\
\hline Number of Samples & Non-Modified Asphalt & $\begin{array}{c}2 \% \text { Graphene } \\
\text { Nano-Platelet } \\
\text { (GNP)-Modified Asphalt }\end{array}$ & $\begin{array}{c}\text { 4\% Graphene } \\
\text { Nano-Platelet } \\
\text { (GNP)-Modified Asphalt }\end{array}$ \\
\hline 1 & 45 & 60 & 61 \\
\hline 2 & 46 & 59 & 60 \\
\hline 3 & 44 & 60 & 60 \\
\hline \multicolumn{4}{|c|}{ British Pendulum Number (BPN) After Wheel Tracking Test } \\
\hline 1 & 25 & 45 & 44 \\
\hline 2 & 23 & 44 & 43 \\
\hline 3 & 24 & 42 & 44 \\
\hline \multicolumn{4}{|c|}{ Percentage Reduction in Skid Resistance } \\
\hline & $47 \%$ & $27 \%$ & $28 \%$ \\
\hline
\end{tabular}

The reduction in the skid resistance due to the polishing of the asphalt surface (caused by the continuous movement of the wheel) is also lesser for GNP-doped asphalt. In the case of the non-modified asphalt, the reduction in the skid resistance was around $47 \%$. On the other hand, the reduction in the skid resistance in the case of $2 \%$ and $4 \%$ GNP-modified asphalt was $27 \%$ and $28 \%$, respectively. This is due to an increase in the stiffness of the GNP-modified binder which improves the structural performance of highways [18]. An improved structural performance ensures the intactness of the macrotexture, resulting in a high skid resistance [10].

Typically, BPN values are obtained in the field after the pavement has been subjected to traffic but, in this case, they were obtained in a laboratory to compare the skid resistance of GNP-doped asphalt with that of conventional asphalt. It is pertinent to mention here that the focus of this investigation was 
to determine the effect of the surface texture/roughness provided by the GNPs on the skid resistance of the asphalt.

\section{Conclusions}

In this study, Graphene Nano-Platelets (GNPs) were added to asphalt to modify its properties. Various tests were carried out to study rheology, moisture susceptibility, temperature susceptibility, bond strength, and skid resistance of the GNP-doped asphalt in comparison to conventional asphalt. Based on the results of the performance testing, the following conclusions have been drawn:

- In comparison to other nanomaterials, Graphene Nano-Platelets are easy to disperse. Unlike GNPs, other nanoparticles (i.e., CBNPs and CNTs) either require high shear mixing or solvent-based dispersion. The usage of smaller percentages of GNPs produces more pronounced results than with other nanoparticles [31]. GNPs save the cost of solvent and high shear mixing, making it possible for pavement engineers to use GNPs for asphalt modification on a larger scale.

- As per the results of conventional testing, GNPs have the potential to reduce the penetration value of asphalt binder by up to $48 \%$ and increase its softening point by up to $19 \%$. The enhancement in these properties can be attributed to the small size and large surface area of GNPs, which aids in stronger bonding. The lower softening point values of the locally produced non-modified binders make them susceptible to rutting during the summers. Upon the addition of $4 \%$ of GNPs, the softening point increases to $57^{\circ} \mathrm{C}$, which is desirable due to the high temperature in Pakistan.

- According to the result of the storage stability test, GNP-modified asphalt binder is stable and can be stored for longer periods without the settling down of the nanoparticles. This makes it suitable for use in the pavement industry.

- Upon the addition of $4 \%$ of GNPs, PG 70 is achieved, which caters to the environmental conditions of Pakistan [13].

- The study of the rheology of the binder shows a significant increase in the stiffness properties of the GNP-modified binder. A maximum increase in the complex shear modulus and a decrease in the phase angle is recorded when $4 \%$ of GNPs are added to the binder. The Superpave rutting factor also increases for the GNP-doped asphalt binder, suggesting a better performance at a high temperature. The elastic nature of the GNPs contributes to this improvement.

- The optimum binder content (OBC) increases with an increase in the content of the GNPs. This trend shows that the initial cost of GNP-modified asphalt would be slightly more than conventional asphalt. But, by observing the modified asphalt performance in the results, we can conclude that doping asphalt with GNPs would reduce the life cycle cost of the pavements. This is due to the fact that pavements in Pakistan fail prematurely. A highway section designed for 20 years sometimes fails within the first two to three years of service because of excessive deformations during summers. GNP-doped asphalt pavements would require far less frequent maintenance or reconstruction cycles, thus positively affecting the life cycle costs.

- The addition of GNPs significantly reduces the temperature susceptibility and increases the resistance to permanent deformation. GNP-modified asphalt shows around a 35\% reduction in the rut depth at a high temperature. At $55^{\circ} \mathrm{C}$, the wheel-tracking slope (WTS) decreased from 0.58 to 0.35 when $4 \%$ of GNPs were added to the asphalt binder. This reduction in the WTS is also suggestive of high resistance to permanent deformation.

- GNPs act as supporting material in asphalt and give it strength, similar to a steel reinforcement in concrete. This leads to an increase in the dynamic modulus of the asphalt. The dynamic modulus of GNP-modified asphalt is around $21 \%$ higher than that of non-modified asphalt, which represents a greater resistance to permanent deformation.

- GNPs significantly reduce the moisture susceptibility of asphalt. The addition of $2 \%$ and $4 \%$ of GNPs to the binder increases the percentage of bitumen coverage from $15 \%$ to $60 \%$ and $70 \%$, respectively. This could be due to the high surface area of the GNPs, which lets them absorb the 
free or available asphalt binder, imparting structural strength to the asphalt [30]. A reduction in the moisture susceptibility indicates high durability of the asphalt.

- The bitumen bond strength test carried out using a PATTI shows that GNPs contribute to improving the adhesive and cohesive bonding of asphalt. The addition of GNPs to binder leads to an increase in the Pull-Off Tensile Strength of around $60 \%$. This can be attributed to the hydrogen bonds and Van der Waals forces in nano-hybrid material [31].The addition of GNPs improves an important safety parameter, the skid resistance, and also increases the asphalt resistance against polishing. The inclusion of the GNPs decreased the percentage reduction of the skid resistance due to polishing from $47 \%$ to $27 \%$. GNPs impart nanotexture to the asphalt, which contributes to enhancing the skid resistance.

The current research on the use of nanomaterials in asphalt mixtures is being carried out in two phases. The first phase involves the laboratory characterization of selected materials. The second phase includes the field investigation through the formation of test tracks in the field exposed to the actual environmental or traffic conditions. This paper presents the findings of the first phase only. The materials shortlisted during the first phase will be subjected to field investigation in the second phase. The handling and transportation of a stiff binder in the field will also be studied. Enhancing the skid resistance of asphalt using GNPs is a new concept and needs further exploration. This will also be carried out in the second phase.

Author Contributions: Conceptualization, N.A.; Data curation, M.H., J.R., and M.F.u.H.; Formal analysis, M.H., N.A., M.A.K., J.R., M.F.u.H., and J.; Investigation, M.H.; Methodology, M.H. and M.A.K.; Supervision, N.A. and M.A.K.; Writing—original draft, M.H.; Writing-review and editing, N.A., M.A.K., J., S.B.A.Z., and M.A.N. All of the authors approved and studied the final paper.

Funding: This research received no external funding.

Acknowledgments: The authors would like to acknowledge the support of the Civil Engineering department at the University of Engineering and Technology, Taxila.

Conflicts of Interest: The authors declare no conflict of interest.

\section{References}

1. Chong, D.; Wang, Y.; Zhao, K.; Wang, D.; Oeser, M. Asphalt Fume Exposures by Pavement Construction Workers: Current Status and Project Cases. J. Constr. Eng. Manag. 2018, 144, 05018002. [CrossRef]

2. Shen, X.; Wang, Z.; Wu, Y.; Liu, X.; He, Y.; Kim, J. Multilayer Graphene Enables Higher Efficiency in Improving Thermal Conductivities of Graphene/Epoxy Composites. Nano Lett. 2016, 16, 3585-3593. [CrossRef]

3. Sharafimasooleh, M.; Shadlou, S.; Taheri, F. Effect of functionalization of graphene nanoplatelets on the mechanical response of graphene/epoxy composites. J. Mater. Des. 2014, 66, 142-149. [CrossRef]

4. Wang, F.; Drzal, L.T. Development of Stiff, Tough and Conductive Composites by the Addition of Graphene Nanoplatelets to Polyethersulfone/Epoxy Composites. Materials 2018, 11, 2137. [CrossRef]

5. Meng, Q.; Kuan, H.; Araby, S.; Kawashima, N. Effect of Interface Modification on PMMA/Graphene Nanocomposites. J. Mater. Sci. 2014, 49, 5838-5849. [CrossRef]

6. Han, M.; Li, J.; Muhammad, Y.; Hou, D.; Zhang, F.; Yin, Y. Effect of polystyrene grafted graphene nanoplatelets on the physical and chemical properties of asphalt binder. Constr. Build. Mater. 2018, 174, 108-119. [CrossRef]

7. Li, J.; Han, M.; Muhammad, Y.; Liu, Y.; Yang, S.; Duan, S. Comparative analysis, road performance and mechanism of modification of polystyrene graphene nanoplatelets (PS-GNPs) and octadecyl amine graphene nanoplatelets (ODA-GNPs) modified SBS incorporated asphalt binders. Constr. Build. Mater. 2018, 193, 501-517. [CrossRef]

8. Le, J.; Marasteanu, M.; Turos, M. Graphene Nanoplatelet (GNP) Reinforced Asphalt Mixtures: A Novel Multifunctional Pavement Material; NCHRP IDEA Project; Transportation Research Board: Washington, DC, USA, 2016. 
9. Brcic, H. Investigation of the Rheological Properties of Asphalt Binder Containing Graphene Nanoplatelets, Norwegian University of Science and Technology, Department of Civil and Transport Engineering. Master's Thesis, Norwegian University of Science and Technology, Trondheim, Norway, 2016.

10. Vaiana, R.; Capiluppi, G.F.; Gallelli, V.; Iuele, T.; Minani, V. Pavement Surface Performances Evolution: An Experimental Application. Procedia Soc. Behav. Sci. 2012, 53, 1149-1160. [CrossRef]

11. Ferrari, A.C. Raman Spectroscopy of Graphene and graphite: Disorder, Electron-phonon coupling, Doping and Nonadiabatic Effects. Solid State Commun. 2007, 143, 47-57. [CrossRef]

12. Hussan, S.; Kamal, M.A.; Hafeez, I.; Ahmad, N.; Khanzada, S.; Ahmed, S. Modelling Asphalt Pavement Analyzer Rut Depth Using Different Statistical Techniques. Road Mater. Pavement Des. 2018, 1-26. [CrossRef]

13. Mirza, M.W.; Abbas, Z.; Rizvi, M.A. Temperature Zoning of Pakistan for Asphalt Mix Design. Pak. J. Eng. Appl. Sci. 2011, 8, 49-60.

14. Khan, K.M. Development of Superpave Performance Grading Map for Pakistan. Life Sci. J. 2013, 10, $355-362$.

15. NHA General Specification. Prepared by SAMPAK International (Pvt.) Ltd.; National Highway Authority: Lahore, Pakistan, 1998.

16. Zou, X.; Sha, A.; Ding, B.; Tan, Y.; Huang, X. Evaluation and Analysis of Variance of Storage Stability of Asphalt Binder Modified by Nanotitanium Dioxide. Adv. Mater. Sci. Eng. 2017, 2017, 6319697. [CrossRef]

17. Abdullah, M.E.; Tun, U.; Onn, H.; Zamhari, K.; Nayan, N.; Tun, U.; Onn, H.; Hainin, M.R. Storage stability and physical properties of asphalt modified with nanoclay and warm asphalt additives. In Proceedings of the Nineteenth Annual International Conference on COMPOSITES/NANO ENGINEERING (ICCE-19), Shanghai, China, 24-30 July 2011.

18. Muniandy, R.; Yunus, R.; Salihudin, H.; Aburkaba, E.E. Effect of Organic Montmorillonite Nanoclay Concentration on the Physical and Rheological Properties of Asphalt Binder. Aust. J. Basic Appl. Sci. 2013, 7, 429-437.

19. Sarsam, S.I. Effect of Nano Materials on Asphalt Cement Properties. Int. J. Sci. Res. Knowl. 2013, 1, 422. [CrossRef]

20. Mashaan, N.S.; Ali, A.H.; Karim, M.R.; Abdelaziz, M. Effect of crumb rubber concentration on the physical and rheological properties of rubberised bitumen binders. Int. J. Phys. Sci. 2011, 6, 684-690.

21. Nazari, H.; Naderi, K.; Moghadas, F. Improving aging resistance and fatigue performance of asphalt binders using inorganic nanoparticles. Constr. Build. Mater. 2018, 170, 591-602. [CrossRef]

22. Sadeghnejad, M.; Gholamali, S. Experimental Study on the Physical and Rheological Properties of Bitumen Modified with Different Nano Materials (Nano $\mathrm{SiO}_{2} \& \mathrm{Nano}_{\mathrm{TiO}}$ ). Int. J. Nanosci. Nanotechnol. 2017, 13, 253-263.

23. Zhang, H.; Gao, Y.; Guo, G.; Zhao, B.; Yu, J. Effects of ZnO particle size on properties of asphalt and asphalt mixture. Constr. Build. Mater. 2018, 159, 578-586. [CrossRef]

24. Mrugała, J.; Chomicz-kowalska, A. Influence of the production process on the selected properties of asphalt concrete. Procedia Eng. 2017, 172, 754-759. [CrossRef]

25. Faizan, M.; Ahmad, N.; Nasir, M.A.; Hafeez, M.; Rafi, J.; Bilal, S.; Zaidi, A.; Haroon, W. Carbon Nanotubes (CNTs) in Asphalt Binder: Homogeneous Dispersion and Performance Enhancement. Appl. Sci. 2018, 8, 2651. [CrossRef]

26. Cai, L.; Shi, X.; Xue, J. Laboratory evaluation of composed modified asphalt binder and mixture containing nano-silica/rock asphalt/SBS. Constr. Build. Mater. 2018, 172, 204-211. [CrossRef]

27. Li, P.; Zheng, M.; Wang, F.; Che, F.; Li, H.; Ma, Q.; Wang, Y. Laboratory Performance Evaluation of High Modulus Asphalt Concrete Modified with Different Additives. Adv. Mater. Sci. Eng. 2017, 2017, 7236153. [CrossRef]

28. Yao, H.; You, Z. Effectiveness of Micro-and Nanomaterials in Asphalt Mixtures through Dynamic Modulus and Rutting Tests. J. Nanomater. 2016, 2016, 2645250. [CrossRef]

29. Leiva-Villacorta, F.; Aguiar-Moya, J.P.; Salazar-Delgado, J.; Loría-Salazar, L.G. Adhesion Performance of Nano-Silica Modified Binder. In Proceedings of the 95th Annual Meeting of the Transportation Research Board, Washington, DC, USA, 10-14 January 2016. 
30. Hsieh, C.; Chen, J.; Kuo, R.; Lin, T.; Wu, C. Influence of surface roughness on water- and oil-repellent surfaces coated with nanoparticles. Appl. Surf. Sci. 2005, 240, 318-326. [CrossRef]

31. Rafi, J.; Kamal, M.A.; Ahmad, N.; Hafeez, M.; Faizan, M.; Asif, S.A.; Shabbir, F.; Bilal, S.; Zaidi, A. Performance Evaluation of Carbon Black Nano-Particle Reinforced Asphalt Mixture. Appl. Sci. 2018, 8, 1114. [CrossRef] 